\title{
Capsular 'pits' in the human lens
}

\author{
M L Harris, N A P Brown, G A Shun-Shin, G T H Smith
}

\begin{abstract}
The lens capsule is an atypical basement membrane surrounding the lens epithelial cells and lens fibres which make up the remainder of the human lens. A seemingly unreported morphological change visible in the lens capsule with the biomicroscope is described.
\end{abstract}

The clinical appearances are of multiple small cystic lesions in the central area of the anterior lens capsule. These are mostly circular and approximately $50 \mu \mathrm{m}$ in diameter; oval and yeast-like shapes are also seen. The overall effect is very reminiscent of the pebbled glass pattern seen in bleb dystrophy of the corneal epithelium. ${ }^{1}$ They are seen most clearly by retro-illumination and exhibit the unreversed effect described by Brown. ${ }^{2}$ From this we can conclude that they are areas of lower refractive index than the surrounding capsule. With focal slit illumination the lesions are localised to the lens capsule with minimal distortion of the underlying anterior clear zone of the lens $(\mathrm{Cl} \alpha)$. When viewed using specular reflection dark areas are evident, with high well defined margins, an appearance similar to moon craters. From this we conclude that they are most probably pits in the front surface of the capsule.

\section{Case reports}

All patients were seen as part of routine toxicity monitoring studies performed at the Clinical Cataract Research Unit, Nuffield Laboratory of Ophthalmology, Oxford.

Figure 1 Pits in the lens capsule photographed by retroillumination.

Illuminating beam from patient's left (patient 2). $B a r=1 \mathrm{~mm}$.

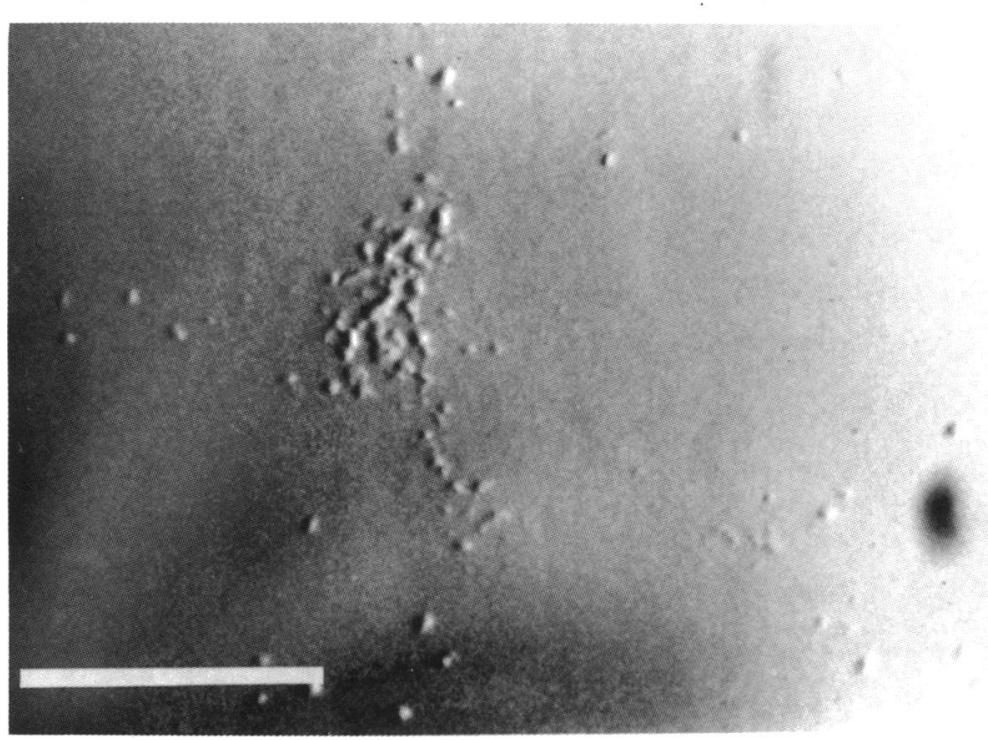

\section{CASE 1}

A 64-year-old woman with a history of coronary thrombosis and systemic hypertension. At the time of examination her medications were: isosorbide dinitrate, atenolol, nifedipine, and simvastatin. Ocular examination was normal except for map-dot dystrophy of the cornea. The capsular abnormalities described above were found in both lenses. The right lens had a few white focal dots, the left lens had grade 1 vacuoles and retro-dots (Oxford grading ${ }^{3}$ ). There had been no visual symptoms and the visual acuity was right eye $-0 \cdot 14$, left eye $-0 \cdot 18$ $\log \operatorname{Mar}(6 / 5,6 / 5+$ Snellen $){ }^{4}$

\section{CASE 2}

A 51-year-old man with a previous history of myocardial infarction and hypercholesterolaemia. At the time of examination his only medication was simvastatin. The visual acuity was right eye $-0 \cdot 10$, left eye $-0 \cdot 14 \log$ Mar $(6 / 4,6 / 4+$ Snellen); he had no visual complaints. Ocular examination was entirely normal except for the lenses; both had some focal dots and peripheral coronary opacities were noted on the right side (Fig 1). In addition both anterior capsules displayed the abnormalities described above.

\section{CASE 3}

A 57-year-old man with a history of myocardial infarction and hypothyroidism. At the time of examination his medication was 1-thyroxine and metoprolol. The corrected visual acuity was right eye $-0 \cdot 08$, left eye $-0 \cdot 10 \log \operatorname{Mar}(6 / 5+6 /$ 4 Snellen); he had no visual complaints. Ocular examination was normal, with grade 1 focal dots in each lens (Oxford grading). Both lens capsules displayed pit-like changes (Fig 2).

\section{CASE 4}

A 49-year-old man with a history of angina pectoris. At the time of examination his medication was atenolol. He had no visual complaints. The visual acuity was $-0 \cdot 10$ right eye, $-0 \cdot 10$ left Log eye Mar (6/4, 6/4 Snellen). Ocular examination showed bilateral pingeculae. There were grade 1 cortical spoke opacities in the left lens and both eyes had pit-like changes in the anterior lens capsules.

\section{Discussion}

The descriptive analysis of the lens by Vogt in his Atlas of Biomicroscopy gives detail of the lens capsule. Attention is drawn to the shagreen pattern seen in the mature lens and to variations in this appearance. ${ }^{5}$ Latterly this has been used to approximate the size of the lens epithelial cells, ${ }^{67}$ and we have used these calculations to estimate the magnitude of the pit-like structures which we have observed. Vogt goes on to describe 


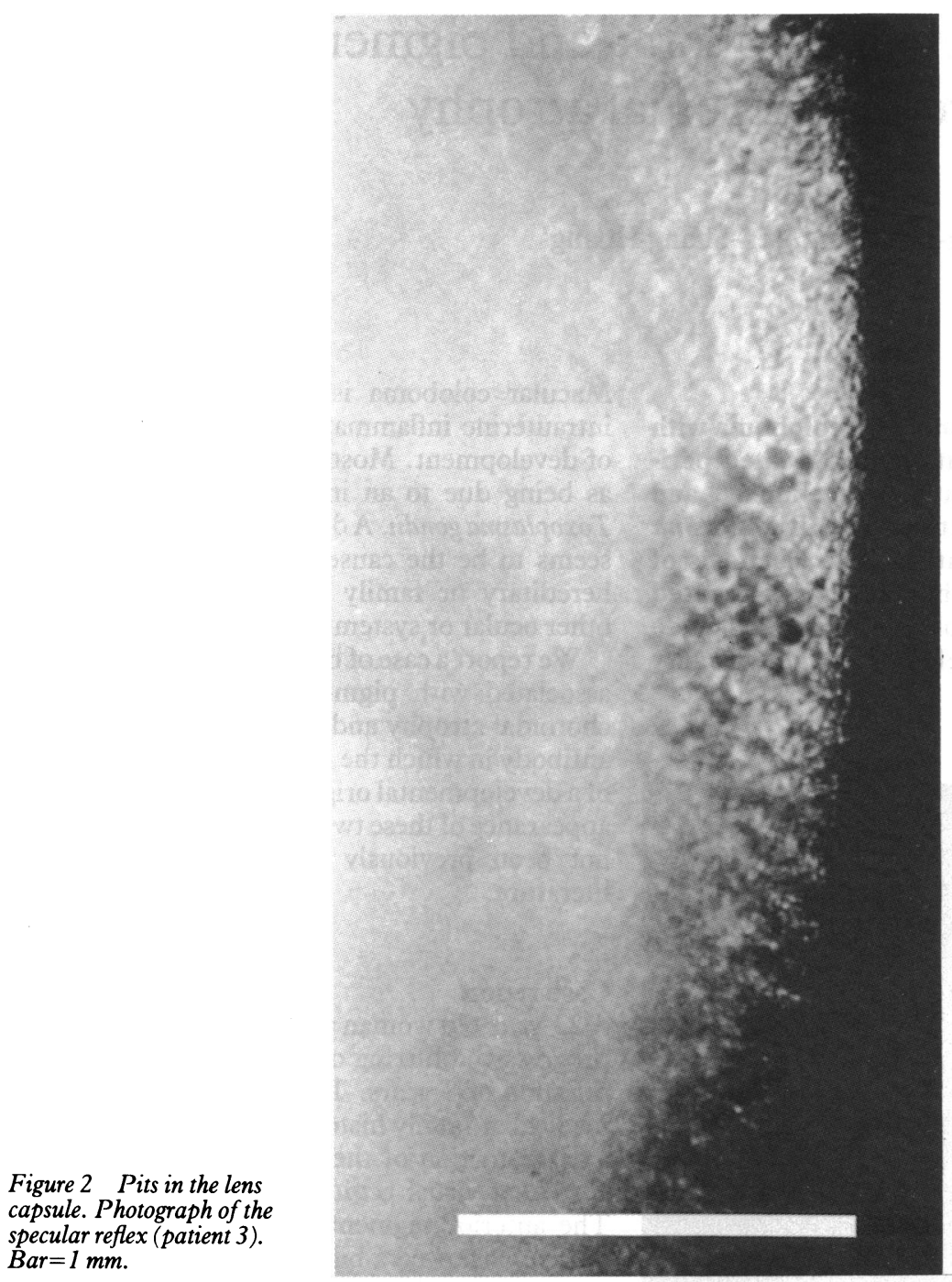
specular re Bar $=1 \mathrm{~mm}$. receptors on the plasma membrane. Fibronectin is a V-shaped molecule with multiple binding sites and has been described as a cell matrix ligand. The molecular architecture of basement membrane consists of laminin and heparan sulphate proteoglycan (HSPG) embedded within a network of type IV collagen. The turnover of basement membrane appears to be slow, about 100 days in the glomerular basement membrane in the rat. ${ }^{9}$ The secretion of basement membranes by epithelial cells appears to be a piecemeál process followed by progressive extracellular self-assembly. ${ }^{\prime \prime}$

The foregoing biochemical evidence suggests two possible pathological mechanisms for lesions within basement membranes. Firstly, errors in biosynthesis and/or metabolism and, secondly, proteolytic attack. In the eyes which we have reported there has been no evidence of inflammatory change or immunological activity to support the second of these mechanisms. The question then arises as to why errors in biosynthesis and/or metabolism should affect the central area of the capsule. There is a further potential pathological influence upon the lens capsule unique to its position within the ocular media - light damage by a photothermal mechanism. Extreme photothermal damage to the capsule produces true exfoliation of the lens capsule, a recognised occupational hazard in those exposed to infrared radiation such as glassblowers and foundry workers. ${ }^{12}$ None of our patients have a history of such exposure. More recently alterations of the anterior lens capsule have been described in association with climatic droplet keratopathy. Frosting of the lens capsule was the first recorded sign followed in more severe cases by plateau formation and in the most severe 'bagging' of the capsule with herniation through the pupil. The severity of the capsular changes was strongly associated with climatic droplet keratopathy, the inference being that the cause was ultraviolet light exposure. ${ }^{13}$ It is possible that the pit-like changes under discussion represent a similar though less marked light induced phenomenon in people from a temperate climate.

1 Bron AJ, Brown NAP. Some superficial corneal disorders. Trans Ophthalmol Soc UK 1971; 91: 13-29.

2 Brown NAP. Visibility of transparent objects in the eye by retroillumination. Brf Ophthalmol 1971; 55: 517-524.

3 Sparrow JM, Bron AJ, Brown NAP, Ayliffe W, Hill AR. The Oxford clinical cataract classification and grading system. Int Ophthalmol 1986; 9: 207-25.

4 Ferris FL, Kassoff A, Bresnick GH, Bailey I. New visual acuity charts for clinical research. Am $\mathcal{F}$ Ophthalmol 1982; 94: 91-6.

5 Vogt A. Lehrbuch und Atlas der Spaltlampenmikroskopie des lebenden Auges. Berlin: Springer, 1931

6 Brown NAP, Bron AJ. An estimate of the lens epithelial cell size in vivo. Exp Eye Res 1987; 44: 899-906.

7 Sasaki K, Kojima M, Hara T. In vivo observation of the crystalline lens capsule. Ophthalmic Res 1988; 20: 154-9.

8 Berlyne GM, et al. Cataracts of chronic renal failure. Lancet 1972; i: 509 .

9 Abrahamson DR. Recent studies on the structure and pathology of basement membranes. F Pathol 1986; 149: 257-78.

10 Cammarata PR, Cantucrouch D, Morrill A, Oakford L. Macromolecular organisation of the bovine lens capsule. Tissue Cell 1986; 18: 83-97.

11 Mohan PS, Spiro RG. Macromolecular organisation of basement membranes - characterization and comparison of glomerular basement membrane and lens capsule components by immunochemical and lectin affinity procedures. F Biol Chem 1986; 261: 4328-36.

Duke-Elder S, MacFaul PA. System of ophthalmology, Vol XIV. London: Kimpton, 1972: 878-81.

13 Johnson G, Minnasian D, Franken S. Alteration of the anterior lens capsule associated with climatic droplet keratopathy. Br F Ophthalmol 1989; 73: 229-34. glycoproteins. For example laminin has areas on the short arms of the molecule which bind to type IV collagen, as well as fitting to identifiable 